\title{
Os Moradores do Bairro Varjão/Rangel como Empreendedores Morais de um Trauma Cultural: reflexões etnográficas sobre ressentimento, ironia e recomposição moral da normalidade normativa
}

Raoni Borges Barbosa ${ }^{a}$

Este artigo analisa os impactos morais e emocionais no cotidiano dos moradores de um bairro popular da cidade de João Pessoa-PB, o Varjão/Rangel, de um crime banal e cruel, entre iguais, ali ocorrido no ano de 2009. A análise parte de relatos etnográficos dos moradores do Varjão/Rangel em relação às várias tentativas e investidas moralizantes sobre seu lugar de pertença, para, assim, buscar compreender a postura ressentida e irônica que se desenvolveu no processo de recomposição moral da normalidade normativa do bairro desde o surto de violência que chocou e envergonhou os moradores do Varjão/Rangel. Trata-se de um esforço em entender a relação tensa de construção de moralidades e de imposição de condutas em relação aos usos morais de uma situação de vergonha-desgraça desde os empreendimentos morais, na forma de um trauma cultural, dos moradores do bairro do Varjão/Rangel.

Falência e recomposição moral, Ressentimento e ironia, Empreendimento e apropriação moral, Bairro do Varjão/Rangel.

Este artigo $^{1}$ analisa os impactos morais e emocionais no cotidiano dos moradores de um bairro popular da cidade de João Pessoa-PB, o Varjão/Rangel, de um crime banal e cruel, entre iguais, ali ocorrido no ano de 2009. O crime em questão, intensamente escandalizado

a Doutor em Antropologia (UFPE). Professor Visitante (FFCS/UERN). Colaborador da Pós-Graduação em Ciências Sociais e Humanas (UERN). Pesquisador associado do BITS/ UERN e vice-coordenador do GREM-GREI/UFPB. E-mail: raoniborgesb@gmail.com. 
pelos empreendedores morais locais da cidade oficial ${ }^{2}$ (a mídia local, a Igreja Católica e a administração pública), foi transformado em uma narrativa moral e moralizante para a apropriação moral do bairro como lugar de degradação, ameaça à ordem social, contágio e falência moral paradigmáticas da pobreza urbana da cidade de João Pessoa, sobre o qual urgia a necessidade de uma ofensiva civilizadora (Regt 2017) .

Nesse sentido, a análise antropológica parte de relatos etnográficos sobre as fofocas e as conversas informais, os silêncios, os interditos e os processos de rememoração e de organização simbólica dos atores e agentes sociais moradores do Varjão/Rangel em relação às varias tentativas e investidas moralizantes de seu lugar de pertença, reconhecimento e interação pessoalizada, para, assim, buscar compreender a postura ressentida e irônica que se desenvolveu no processo de recomposição moral da normalidade normativa do bairro passados nove anos desde o ato de violência que chocou e envergonhou os moradores do Varjão/Rangel ${ }^{4}$. Trata-se, com efeito, de um esforço em entender a relação tensa de construção de moralidades e de imposição de condutas em relação aos usos morais de uma situação de vergonha-desgraça (Scheff 1990) para empreendimentos morais de reconfiguração, real ou imaginária, da cultura emotiva e dos códigos de moralidade de um lugar tido como problema e como problemático para a imagem oficial e pública de cidade.

A presente discussão enfatiza as ações e discursos de empreendedorismo moral da mídia local como agente produtor e divulgador de uma narrativa moral e moralizante de Chacina do Rangel, e da administração pública enquanto sistema estatal de produção da justiça e de judicialização da narrativa midiática, por um lado; e as ações e discuros de empreendedorismo moral dos moradores do Varjão/ Rangel, enquanto agentes de uma narrativa local e inversa de trauma cultural $^{5}$. Nesse sentido, os dados etnográficos foram produzidos de modo a enfatizar o quanto as narrativas moralizantes, oficiais e oficiosas, aconteciam no caos simultâneo característico da vida real de 
atores e agentes sociais concretos, mas, também, como esta narrativa inversa de trauma cultural dos moradores do Varjão/Rangel, apesar de ter desenvolvido dinâmicas e colorações próprias, paulatinamente se nutria do empreendedorismo moral da cidade oficial: da mídia local e da administração pública da justiça.

No âmbito da proposta analítica da antropologia da moral e das emoções, o presente artigo explora a lógica actancial e das estruturas de reciprocidade (positivas e negativas) de moralidades locais e culturas emotivas (a de um bairro popular e a de uma cidade oficial) em disputa e equivocação. Processo este percebido desde um instrumentário teórico-metodológico simbólico-interacionista que enfatiza a análise de situações de crise e falência moral, de liminaridade, de recomposição moral e emocional e de reinvenção de pactos sociais e figurações públicas de sentimentos, narrativas e imputações de responsabilidades.

\section{'Aqui foi uma banda do céu que caiu'}

A formação do bairro do Varjão/Rangel teve início nos anos de 1920. Atualmente o bairro ainda abriga moradores oriundos, em sua maioria, de cidades interioranas da Paraíba e de estados vizinhos, em constante fluxo. A presença de um ethos interiorano tensionado pelas exigências modernizantes da cidade de João Pessoa pode ser percebida tanto na forma do consumo dos espaços públicos quanto em expressões e modos de falar próprios de regiões interioranas da Paraíba.

O processo de ocupação dos espaços se organiza mediante a invasão de áreas devolutas ou de áreas públicas e de proteção ambiental. Os efeitos deste processo são verificados no padrão de ocupação de áreas vulneráveis e de risco a partir de técnicas populares de autoconstrução. Ali os moradores se concentram em suas pequenas casas e puxadinhos, desenhando ruas desalinhadas, vielas e becos de barro batido, onde uma intensa vida familiar e vicinal acontece e um espaço de interações pautado na lealdade, na intensa pessoalidade e no monitoramento recíproco constante se realiza (Koury 2016; Barbosa 2015). 
O evento trágico Chacina do Rangel pode ser considerado um divisor de águas na história do bairro do Varjão/Rangel e nas memórias dos moradores. Desde o fatídico nove de julho de 2009 em que o crime entre iguais se consumou, o tema ainda permanece tabu e objeto de vergonha e silêncio, mas também como objeto e momento de reflexão sobre as promessas feitas e, no mais das vezes, não realizadas, pelos empreendedores morais ${ }^{6}$ locais - a mídia local, a Administração Pública, a Igreja Católica - que se aventuraram na apropriação moral e moralizante do crime de chacina como narrativa dramática de Chacina do Rangel.

O exercício etnográfico de perceber e compreender os interditos, os breves desabafos e as sutis ironias e ressentimentos que compõem as memórias locais sobre este momento crítico das sociabilidades pessoalizadas e engolfadas de uma figuração social pobre e estigmatizada - mas bastante preocupada em manter e preservar suas fachadas individuais e coletivas de pessoas de bem que lutam pelo reconhecimento moral da cidade de João Pessoa - foi possível somente mediante um conjunto de estratégias metodológicas entrecruzadas. Estas estratégias combinaram procedimentos de observação direta do local do crime e arredores, a montagem de um banco de imagens sobre crimes banais e cruéis ocorridos na cidade de João Pessoa, passeios diversos pelo bairro do Varjão/Rangel e levantamento histórico, geográfico e sociopolítico de acontecimentos pertinentes no bairro.

O crime de chacina apontava, em síntese, como relataram os moradores vizinhos e próximos das famílias então vítimas e agressoras, de um infeliz crime entre iguais, motivado por banalidades, ressentimentos e mágoas cotidianos (Koury et al. 2010 e 2013) espiralados até uma situação limite das vulnerabilidades interacionais ${ }^{7}$ (Goffman 2012) ou ponto de não retorno (Alberoni 1981) em que as ofensas morais (Cardoso de Oliveira 2008 e 2011) reciprocamente trocadas tornaram-se um sentimento insuportável de vergonha-desgraça (Scheff 1990) canalizada como ira-raiva (Scheff \& Retzinger 1991) e, ato contínuo, como violência contra o outro próximo (Coelho 2010). A dinâmica interna 
do crime de chacina deve ser compreendida no âmbito relacional da figuração social mais ampla em que o mesmo veio a se materializar como objeto de interesse para a apropriação moral e emocional da pobreza urbana.

Esta figuração social prenhe de tensões e vulnerabilidades interacionais deve ser compreendida, por sua vez, a partir de suas formais sociais mais influentes para o comportamento individual cotidiano, como a Rua Oswaldo Lemos (local do crime), caracterizada pelas suas relações primárias extensas e de intensa copresença, e como a própria vizinhança em que agressores e vítimas estavam envolvidos em fortes vínculos de solidariedade e reconhecimento. Mas também de dívidas morais e de estratégias de evitação e de descrédito velado das hierarquias, distâncias e deveres assumidos pelos atores e agentes sociais em jogo comunicacional, tais como: a jocosidade, o bullying, as justificativas de si e as acusações do outro, as pequenas agressões à propriedade e às pessoas, as ofensas morais reiteradas e etc.

Esta intensa pessoalidade entre os moradores é característica das sociabilidades em todo o bairro do Varjão/Rangel, fortemente ligados por vínculos de parentesco e compadrio, lealdade e amizade, confiança e dádiva, em redes engolfadas de interdependência; assim como a copresença continuada em ruas estreitas que abrigam vilas e residenciais conjugados, com portas e janelas quase que se invadindo. A intensa pessoalidade e as redes engolfadas de interdependência, somadas ao estigma que pesa sobre a sociabilidade de identidade dupla e dúbia do bairro, constituem e potencializam as vulnerabilidades interacionais e as possibilidades sempre presentes de insulto moral características daquele espaço interacional.

O Varjão - sempre conhecido na cidade como sociabilidade problemática e violenta e como moralidade degradada - se opõe ao Rangel como esforço positivo dos moradores de moralização e integração do bairro à cidade. Varjão e Rangel, portanto, representam lugares e narrativas que buscam a invisibilização do outro em um mesmo espaço de relações (Barbosa 2015). 
Enquanto que o primeiro, o Varjão, remete a uma ideia de paisagem e de espaço ainda a ser colonizado pela ação humana civilizada: a grande várzea do Rio Jaguaribe, situada, em épocas passadas nas franjas da cidade; o segundo lugar, o Rangel, enfatiza, por um lado, a presença imaginária de uma família tradicional e destacada na cidade de João Pessoa como proprietária das terras em que se desenvolveu o bairro e, também, como um dos elementos humanos civilizadores do espaço, assim como, por outro lado, a nominação Rangel reforça o projeto coletivo dos moradores pela conformação das antigas comunidades da várzea do rio como bairro integrado moral, administrativa e economicamente na cidade de João Pessoa.

Nesse sentido, Varjão, Rangel e Varjão/Rangel não são nominações que representam complementaridades, acordos ou jogos de alianças entre possíveis leituras de passado e de projetos de futuro, mas como imagens de lugares sobrepostos em um mesmo território e que se chocam em disputas morais e identitárias inconclusas. Estas tensões são oportunamente utilizadas pelo morador para se identificar e para se desidentificar em situações variadas de envolvimento cotidiano.

O Varjão é consensualmente tido como o espaço dos engraçadinhos (jovens conhecidos e problemáticos, que perambulam pelo bairro e se envolvem com pequenos ilícitos), da mundiça (famílias que apresentam comportamentos moralmente reprováveis, como a prática de escandalização de intimidades, de problemas com drogas e dívidas e de usos de espaços públicos tidos como inapropriados), da violência entre figuras desviadas (bêbados contumazes e pequenos bandidos), problemáticas ou mesmo vergonhasamente degradadas à condição de não pessoas (como os mendigos que vivem nas proximidades do mercado público do bairro, dormindo nas calçadas e alimentando-se das sobras da feira).

Não se faz possível diferenciar bons e maus, estabelecidos e outsiders no Varjão/Rangel, haja vista que não há um centro difusor e impositor de uma etiqueta tida como superior e mais sofisticada. As fronteiras e hierarquias visíveis e invisíveis são móveis e não se apresentam de 
forma unívoca e rígida, de modo que o estigma se distribui por todo o bairro na forma de acusação sempre possível de enunciação do outro como Varjão. As estratégias de identificação e de integração no bairro dependem de onde parte a construção simbólica dos atores e agentes sociais em processo de negociação, disputa e apropriação moral recíproca, isto é, da definição da situação e do outro (Adams 2007).

O cenário do crime de chacina transformado na narrativa pública e dramática da Chacina do Rangel, portanto, é o da pobreza urbana em um bairro periférico central. Cenário este que apresenta ainda resquícios acentuados de uma convivência comunal fortemente pessoalizada e mesmo engolfada (Scheff 1990). As famílias e vizinhos, ali situados há três ou quatro gerações, convivem em uma grande abertura para o intercâmbio de intimidades e de dádivas, tal como se percebe nos gestos de solidariedade e de confraternização entre vizinhos e na circulação de crianças e jovens pelas casas.

Não raro se verifica grupos de jovens que varam à noite despreocupados jogando com seus consoles, nos terraços abertos, assim como rodas de conversas no adentrar da madrugada e 'moitinhas' de compadres que levam para passear os seus passarinhos, utilizando-se do ar revigorante que chega da Mata do Buraquinho e da 'praçinha' que se tornou o inconcluso Monumento à Paz improvisado no local exato da chacina $^{8}$. O contexto engolfado da sociabilidade Varjão/Rangel, de intensa pessoalidade, copresença acentuada e forte monitoramento recíproco do comportamento do outro relacional, com efeito, é mediado por uma postura de discrição e de respeito às reputações.

Este Nós relacional formado por laços bastante estreitos, assim, é o elemento social que preenche a Rua Oswaldo Lemos com uma gramática moral e emocional própria: a do respeito à fachada coletiva de todos enquanto moradores do lugar e à fachada do outro individual com quem muitas vezes se compartilha o lugar de trabalho, e da solidariedade entre vizinhos em um contexto quase que familiar. Diferentemente, portanto, das sociabilidades urbanas periféricas tomadas pela grande violência do tráfico de drogas e das gangues juvenis, a Rua 
Oswaldo Lemos não se caracteriza por fenômenos de violência urbana crônica como toques de recolher ou pela Lei do Silêncio?.

No caso do crime de chacina transformado na narrativa de Chacina do Rangel, a violência intensamente cruel se deu entre pessoas não somente socialmente iguais, mas extremamente próximas e que se conheciam e desde muitos anos como moradores da Rua Oswaldo Lemos e do bairro do Varjão/Rangel. A ruptura total dos laços afetivos entre as famílias envolvidas no crime não ocorreu em razão de dívida de jogo ou de transgressão aos códigos impositivos dos senhores do tráfico de drogas, de modo que o evento pudesse ser justificado a partir da narrativa policial típica de execução de mais um endividado com o tráfico em uma 'boca de fumo', tal como aconteceu no caso da notícia supracitada.

Da mesma forma que não havia entre as famílias qualquer disputa por bens econômicos que pudesse desatar desentendimentos movidos por cálculos econômicos e tamanha fúria destruidora entre os seus membros. Agressores e vítimas partilhavam de um mesmo mundo social, compartilhando, no caso do homem adulto de cada família, do mesmo ofício de gesseiro em uma fabriqueta de gesso improvisada ali mesmo na casa da família chacinada, na Rua Oswaldo Lemos ${ }^{10}$. Os filhos de ambos os casais brincavam conjuntamente, assim como as respectivas esposas e donas de casas conviviam intensamente no cuidado dos filhos, na realização das tarefas da casa e nos contatos com os vizinhos e parentes da rua e da vizinhança.

Longe de um contexto interacional e situacional marcado pela grande violência ou pela discórdia passível de observação racional por terceiros, a violência banal entre iguais da Chacina do Rangel se assemelha mais a um desentendimento familiar que fugiu ao controle dos interactantes, já bastante excitados pelo espiral crescente de provocações reciprocamente dirigidas, mas que, do início ao fim, permanece como tensão e disputa moral e emocional de arranjos e recursos internos e íntimos às famílias envolvidas no crime ${ }^{11}$. Os instrumentos domésticos utilizados como armas brancas pelo casal agressor - um 
facão e uma faca peixeira de cozinha - assim como o grau de desorganização e de improvisação das ações violentas verificadas na cena do crime, revelam um contexto interacional pessoalizado, perpassado por quebras de confiança ${ }^{12}$ e pequenas mágoas e ofensas morais acumuladas, muitas vezes silenciadas e que, em uma situação-limite de fúria e de ira-raiva (Scheff \& Retzinger 1991; Coelho 2010), despontou como desfiguração moral e violência destruidora do outro próximo tido como extensão de si mesmo.

O acúmulo de pequenas mágoas entre estes atores e agentes sociais remete a um contexto de potencialização das vulnerabilidades e fragilidades interacionais até sua configuração como situação-limite e ruptura com a normalidade normativa. O convívio dos agora assassinos e vítimas em regimes de intensa pessoalidade e acentuada copresença indica uma situação de engolfamento das personalidades, ou seja, um contexto interacional em que os atores e agentes sociais em jogo comunicacional ${ }^{13}$ se vêem em situações não de todo controladas e que se expõem perigosamente à ambivalência das ações individuais, podendo estas ser interpretadas e antecipadas como ameaça a si próprio e ao grupo de atores e agentes sociais envolvidos na situação.

O casal de criminosos era ligado à família chacinada por fortes laços de parentesco e compadrio. Estes laços, não somente de sangue, mas de gratidão (Simmel 2010) e de fidelidade (Simmel 2003), vêm a ser o elemento desfeito na micropolítica cotidiana das emoções (Rezende \& Coelho 2010) do caso em tela. Este processo intersubjetivo de construção de sentidos sociais se reforça no acúmulo de pequenas mágoas e desentendimentos que redundam em ressentimentos profundos, quebra de confiança e tem como desenlace a violência entre iguais que caracteriza a destruição de vínculos de intensa proximidade e pessoalidade, em que o Eu e o Outro se constroem enquanto extensão um do outro, como projeto coletivo e moralidade específica.

Esta socialidade primária (Park et al. 1925; Berger 2001), com suas hierarquias invisíveis, estaria baseada em uma forte solidariedade e reciprocidade nas ações comuns em ambas as famílias vizinhas, como 
por exemplo, as trocas de favores, o cuidado compartilhado dos filhos e as refeições diárias feitas conjuntamente. Havia, também, fortes laços e grandes expectativas que uniam Carlos José e Moisés Soares no local de trabalho e na convivência na Rua Oswaldo Lemos, ou seja, no mundo da vida de forma mais ampla. Conforme consta no Processo Judicial referente à Chacina do Rangel (Processo No 200.2009.023.1255, locado no Fórum Criminal, Comarca de João Pessoa, $1^{\circ}$ Tribunal do Júri - Chacina do Rangel) $)^{14}$ :

Interrogatório (Folhas 259-264)

- Carlos José: residente na Rua Oswaldo Lemos, 70, bairro do Rangel; operador de máquina; sem antecedentes criminais; trabalhava como gesseiro na companhia de Moisés e Antonio, cunhado de Moisés e conhecido como João; tinha uma relação amistosa como Moisés e um não mexia com o outro; foi demitido, mas saiu de cabeça erguida; Moisés e João ficaram com piadinhas e ele foi tomar satisfação; Moisés lhe teria dito para se afastar, senão o cortaria com um facão; que nunca mexeu com Priciano e com a família, mas chegou a lhe dar um cascudo, porque Priciano mexia com ele; Moisés disse que falaria com João sobre o caso e que daria parte de Carlos, que ele sentiria o peso da mão de Moisés; diante disso Carlos começo a se amedrontar; houve também uma discussão por conta de uma galinha que Moisés teria matado e jogado no quintal de Carlos; que Edileuza o aconselhava a dar parte de Moisés, enquanto João aconselhava Moisés a dar parte de Carlos;

VII - Pode contar todos os demais fatos e pormenores que conduzam à elucidação dos antecedentes e circunstâncias da infração?

R. [...] QUE ficou sem sono e de repente deu um negócio na sua cabeça impulsionando o acusado para ir até Moisés; QUE o interrogado resolveu pegar um facão e uma peixeira e desceu para casa de Moisés; QUE foi direto para o quarto de Moisés, onde este estava com a esposa e a criança [...]QUE o acusado nunca tomou remédio controlado, nunca foi interno de colônia alguma e nem nunca foi considerado doido [...].

VIII - Tem algo mais a alegar em sua defesa?

R. QUE tem a dizer ainda que se desculpa perante todo o Brasil porque não tinha a intenção de fazer mal a esses meninos e a mulher, e que estava apenas com muita raiva de Moisés [...] (Folhas 260-261). 
- Edileuza de Oliveira dos Santos: residente na Rua Oswaldo Lemos, 70, Rangel; do lar; sem antecedentes criminais; nega as acusações; somente Carlos participou do crime [...];

VII - Pode contar todos os demais fatos e pormenores que conduzam à elucidação dos antecedentes e circunstâncias da infração?

R. QUE passou a conhecer Divanise quando esta começou a pedir a interrogada que quando ela tivesse uma roupinhas de menino usada a ela para ela dar aos filhos para usarem; [...] QUE em princípio a convivência era harmoniosa mas depois começou a surgir pequenos incidentes originando-se do fato de que Priciano ficava apelidando o filho de Isael da interrogada; QUE ficava chamando de "Djalma" (nome de um tio doente mental de Isael) e outros apelidos de menor importância; [...] QUE quando Carlos soube deste fato uma certa vez deu um cascudo em Priciano; QUE isso gerou descontentamento na família e passaram a mandar Moisés dar parte de Carlos mas Moisés nunca deu; [...] QUE informa também que meses antes deste fato quando ainda estava grávida do seu filho recém-nascido o acusado lhe deu uma galinha com vários pintos; QUE a acusada passou a criar e que dias depois a galinha desapareceu; QUE a interrogada ficou triste e o seu cunhado chegou dizendo que tinha visto a galinha morta no quintal da casa de Moisés; [...]QUE a interrogada comentou para o seu marido, mas Carlos veja só bonito pra você matou esse povo, agora você vai ser preso e eu posso ser presa também porque sou sua mulher [...] (Folha 264). - Contra-Razões da Apelação de Carlos José Soares de Lima, por parte do Ministério Público:

Folhas 525/527

Argumenta a defesa a existência de animosidade entre o recorrente e uma das vítimas (Moisés), que teria culminado até mesmo em ameaças de morte [...].

Primeiramente, alegou que a inditosa vítima, no ambiente de trabalho, "lhe aperreava, lhe xingava". Depois, teria pego uma galinha de sua propriedade e matado, somente para provocar-lhe. Por fim, depois de uma discussão ocorrida entre os filhos de ambos, em que o recorrente deu um cascudo em Priciano, filho da vítima, este o teria ameaçado de morte, evento, todavia, verificado cerca de quinze dias antes dos crimes investigados neste processo.

[...]

Na hipótese em descortino, o que causou aborrecimento nos acusados foi justamente as "brigas e arengas" entre as crianças, filhos do casal vítima e acusado [...] que torna o motivo totalmente despro- 
porcional em relação ao crimes, em vista de sua banalidade.

- Relatório da Apelação Criminal de Carlos José Soares de Lima e de Edileuza de Oliveira dos Santos, por parte do Tribunal de Justiça, Gabinete do Desembargador:

Folha 581

Toda querela surgiu pelo fato dos filhos dos ora denunciados e dos do casal Moisés Soares Forte e Divanise Lima dos Santos se apelidarem mutuamente. Como resultado desta prática, que é comum entre crianças e adolescentes, o acusado Carlos José Soares de Lima passou a ser chamado de 'CEGO', em referência à sua deficiência visual, o que o incomodava, bem como a sua esposa, a acusada Edileuza Oliveira dos Santos, popularmente conhecida por 'LEDA'. Já a vítima Priciano Soares dos Santos, um dos filhos das vítimas Moisés Soares Forte e Divanise Lima dos Santos, constantemente era alcunhado de 'MACACO' e 'NEGRO SAFADO', dentre outros adjetivos degradantes, humilhantes e com caráter discriminatório. [...] por conta desta intriga, Carlos José Soares de Lima já tinha agredido fisicamente Priciano Soares dos Santos com um cascudo [...] ao que parece, o que motivou a decisão de praticarem os delitos, o que fizeram na forma premeditada, fato batizado pela imprensa e pela sociedade como a 'CHACINA DO RANGEL'.

A chacina aqui etnografada como situação-limite - situação social em que as vulnerabilidades interacionais desbordam para processos totais de ruptura de vínculos e de processos de violência física e simbólica - deve ser entendida em um contexto definido e interpretado pelos atores e agentes sociais envolvidos como de quebra de confiança e de vergonha-desgraça. Cada ator e agente social, como homem total, participa das tramas relacionais e interacionais da cultura emotiva de uma sociabilidade dada, sendo, assim, atingido pelos processos de escândalo e contágio social das reciprocidades positivas e negativas.

O crime entre iguais, vizinhos próximos e ligados por vínculos de afinidade e parentesco, que se frequentavam mutuamente, nesse sentido, chocou e escandalizou os moradores do bairro em razão da combinação enigmática de violência absurdamente cruel e de motivação banal da ação violenta, entendida de forma imediatista pela platéia que se deparava com os corpos mortos desfigurados naquela cena 
de horror e que desesperadamente buscava uma forma de retorno à normalidade normativa. Como enfatizou uma vizinha dos autores da chacina e da família vitimada, Dona Neusa ${ }^{15}$ : "chocou a vizinhança toda, geral".

Este episódio banal de desentendimentos e buscas de explicações, assim, termina com uma chacina em que Moisés Soares Forte, Divanise Lima dos Santos, grávida de gêmeos, e mais três filhos foram cruelmente assassinados. Essa narrativa midiática da tragédia foi lida, no processo judicial, e comunicada à população de João Pessoa, com ênfase na lógica actancial dos agressores: eles aparecem como que guiados por sentimentos de humilhação canalizados para uma violência destruidora do outro próximo, outrora íntimo e confidente, mas que gradualmente, em razão de processos de quebra de confiança, se transformara em uma imagem espelhada e moralmente invertida de si mesmo.

A narrativa midiática mais geral, por sua vez, enfatizava a irracionalidade, a monstruosidade e a crueldade da violência banal entre os iguais, percebidos como elementos imprevisíveis e perigosos da pobreza urbana. De acordo com notícias de um jornal on-line:

"O cenário do crime revela a verdadeira carnificina. Crianças degoladas e partes dos corpos separados por golpes de facão em vários locais da residência. Uma mão de uma das crianças foi encontrada em cima de um guarda roupa da residência" (ClickPB 2009).

O crime de chacina, pela sua enigmática combinação de motivação banal e de violência cruel, foi recepcionado pelos moradores próximos, do Varjão/Rangel em geral e bairros adjacentes, como uma profunda quebra de confiança. A quebra de confiança por parte do outro relacional que ultrapassa o costume, a lei ou a moralidade de forma irrecorrível, tornando-se ele, assim, um indivíduo ameaçador, impuro, sujo, perigoso e contaminador, pode vir a se configurar nos contextos mais banais da sociabilidade cotidiana do homem simples, como também configurar atos terriveis de perversão e violência contra o outro. É neste sentido que o Monstro do Rangel apareceu para a cida- 
de e para o bairro como agente do mal, monstro, animal, figura a ser extirpada da comunidade humana e do âmbito do sagrado.

Os autores do crime de chacina tornaram-se - na narrativa pública e dramática de Chacina do Rangel dos empreendedores morais da cidade de João Pessoa - o bode expiatório oportuna e convenientemente construído para uma cruzada moral (Gusfield 1986) pela captura da pobreza urbana como elemento de ameaça e perigo. A partir deste argumento a mídia local logrou escandalizar, em um primeiro momento, a multidão de vizinhos que acudiram à cena do crime e que, então, passaram a definir a situação do crime entre iguais como surto descivilizador, pânico e falência moral, de modo que a reparação da normalidade normativa e da ordem cosmológica, no bairro e na cidade, reclamava uma ofensiva civilizadora sobre o bairro do Varjão/Rangel: o paradigma da pobreza urbana moralmente degrada e contagiosa.

A potencialização da estigmatização do lugar Rangel foi sentida pelos seus moradores na medida em que a cidade de João Pessoa desconstruiu o esforço de dissociar a nominação Rangel do contexto Varjão de sociabilidade de baixo padrão moral. Ainda nas palavras de Dona Neuza, a tragédia "chocou a vizinhança toda, geral. E finalmente esse negócio abalou o mundo geral. Aqui foi uma banda do céu que caiu".

A fala desta moradora, ao afirmar o sentimento de vergonha-desgraça (Scheff 1990) e de humilhação como forma de julgamento moral do morador do bairro em face da tragédia amplamente escandalizada pela mídia local, situou este momento de ruptura na sociabilidade do bairro em relação a um passado em que as nominações Varjão e Rangel eram tidas como minimamente dissociadas no imaginário que o morador alimentava sobre o como era visto e classificado moral e emocionalmente pela cidade de João Pessoa. O Varjão/Rangel passou a ser encarado como um lugar ainda mais problemático e a ser pacificado com urgência, principalmente pela ação policial e pela reconfiguração moral e emocional do crime ali ocorrido, tanto de uma perspectiva religiosa quanto de uma perspectiva laicizante de retomada do lugar. 


\section{O Rangel é o bairro do amor}

No caso etnografado, percebe-se como o bairro do Varjão/Rangel, considerado pelos empreendedores morais da cidade oficial como objeto da cruzada simbólica, aparece, também, como ator e agente social coletivo que busca impor projetos e reafirmar memórias próprias de um lugar de pertença, participando da cruzada simbólica como uma narrativa moralizante também sua, mas em sentido contrário ${ }^{16}$. Ao assumir o discurso de uma cruzada moral fortemente moralizante que busca apropriar-se da pobreza como problema urbano e como questão de controle social, o esforço do morador, no sentido inverso, busca a afirmação de uma dignidade do bairro, enfatizando as fronteiras e hierarquias morais que separam os bons e os maus, o morador de bem e o monstro social. O lugar Varjão, assim, está sempre mais além do horizonte do lugar Rangel, como uma sombra que se projeta para frente, embaçando os projetos futuros.

Acometidos pelo acentuado sentimento de vergonha-desgraça e de humilhação causado pela associação do nome Rangel ao ato perverso da chacina, os moradores do bairro buscaram, desde que sentiram a denominação Chacina do Rangel como o enlamear o esforço coletivo de restauração da imagem do bairro através da imputação do nome Rangel à chacina, dissociar a imagem do bairro da prática perversa de crueldade de um monstro, e, por conseguinte associar a atividade monstruosa ao nome Varjão, que já era, em si, carregado moral e emocionalmente como signo de incivilidade e de violência. Nesse sentido, os moradores se posicionaram na cruzada moral instalada de moralização e de civilização das áreas de pobreza urbana e se esforçaram em demonstrar que nem toda pobreza deveria carregar esse estigma. Ao mesmo tempo, buscavam retornar à sua luta de dignificação do bairro através da nominação Rangel.

As estratégias de desculpa, de evitação e de preservação da fachada, comuns em situações de liminaridade, despontam no discurso do morador do Varjão/Rangel que se utiliza do jogo moralizante do 
empreendedor moral da cidade sobre o lugar da chacina - mas não sobre o seu lugar de pertença - para, a partir dele, poder estabelecer-se de volta na sua luta pela dignidade do lugar em que habita, o Rangel, dissociando-o do lugar da chacina. Este morador participa ativamente das chamadas da mídia e de outros empreendedores morais para a limpeza simbólica do espaço onde ocorreu a chacina, com a destruição da casa dos agressores, vista como demonizada, e com a purificação da casa das vítimas.

O morador do Varjão/Rangel também aderiu à ideia de construção de um santuário no local da chacina; e apresentou-se hostil à sociedade civil posicionada contra a cotidianidade de tortura nos presídios da cidade, após a viralização de um vídeo em que agentes penitenciários torturam o agressor considerado como o autor principal da chacina, o Carlos José Soares de Lima (batizado pela mídia local de Monstro do Rangel). $O$ morador seguiu em comitiva ${ }^{17}$ até o governador para solicitar a manutenção do diretor do presídio onde ocorreu a tortura, dizendo que torturar foi pouco e que devia era ter matado o assassino, o demônio encarnado.

Todas estas incursões no cenário político que se tornou a chacina tiveram por intenção a separação do lugar de pertença, onde moram, do espaço da chacina, lugar associado ao mal e à maldade. Com isso os moradores pensaram poder retornar à luta para a inserção do seu bairro, o Rangel, na cidade, como um lugar de gente de bem. Esta lógica de ordenamento moral e emocional pela reafirmação da diferença entre o morador do bairro como gente de bem e o morador problemático que mancha e suja a fachada do bairro pode ser vista na forma irônica e ressentida em que os problemas reais e imaginários do bairro são publicamente denunciados.

A ironia aparece, em Goffman (1998), como uma modalidade de discurso que a um só tempo aproxima e afasta o sujeito de fala do evento crítico ou situação-limite que este relata. Trata-se de uma postura moral que combina o envolvimento crítico e o desengate oportuno de cadeias de interdependência. 
No entender de Werneck (2015), a ironia é uma competência de atores e agentes reflexivos em situação crítica, mas também um dispositivo moral capaz de conciliar possibilidades de crítica a uma situação específica, sem, contudo, ocasionar rupturas na rotina dos atores e agentes sociais. A ironia, ou jocosidade, faz parte do jogo oficioso e público de desculpas e acusações em um cenário tensional e ambíguo, onde bons e maus não se diferenciam facilmente (Hughes 2013), de modo que "a crítica é apresentada como se não fosse séria ou relevante, mas proporcionando ainda assim, a colocação de algo [de uma situação dada] em questão" (Werneck 2015:4).

O ressentimento, por sua vez, é uma experiência de rebaixamento moral acentuado, que remete a "um tempo repetitivo gerador de fantasmas e pensamentos hostis vividos na impotência" (Ansart-Dourlen 2004:351). O ressentido se encontra em uma situação de engolfamento resultante de um trauma, injustiça, quebra de confiança e vergonha-desgraça que desorganiza simbólica e materialmente seu espaço de relações e sua capacidade de narrar o passado e de projetar o futuro em conformidade com seus critérios próprios de definição da situação.

Nessa lógica de ação discriminadora, o morador do bairro do Varjão/Rangel buscou utilizar o discurso de estigmatização e de vergonha-desgraça de que o bairro foi acometido para um esforço de diferenciação entre o lugar da pertença e o lugar da chacina: o lugar do morador de bem do lugar do monstro. A liminaridade, com isso, se situa no contexto situacional e interacional de relações em que o morador entra no jogo do empreendedor moral de intervenção civilizatória no bairro, mas direciona esta intervenção sobre o lugar da chacina, de modo a dissociá-lo da normalidade normativa do bairro do Rangel.

Trata-se, assim, de uma dinâmica pública de disputas morais em que a liminaridade aparece em seu aspecto duplo de vergonha-desgraça e de retorno à luta pela dignidade. Este jogo de desculpa de si e de acusação do outro foi construído em torno de uma narrativa de trauma cultural (Alexander 2004): um empreendimento moral difuso e aparentemente anônimo, que se realiza no modo silencioso da fofoca, da acusação e da rejeição ressentida e irônica do agressor. 
A narrativa de trauma cultural do morador do Varjão/Rangel, nesse sentido, denuncia ironicamente os momentos de quebra de confiança gerados pelos empreendedores morais da cidade em suas investidas sobre o bairro enquanto recurso simbólico e material estratégico para a cidade $^{18}$. Elemento de ressentimento e medo para o morador do Varjão/ Rangel, o lugar do crime, com todas as tentativas de apropriação simbólica e com todas as transformações inconclusas porque passou, permanece como espacialidade e temporalidade em suspenso e terrivelmente liminar: tanto aponta para uma possível retomada de intervenções no bairro por parte dos empreendedores morais locais, quanto provoca o ressentimento irônico do morador que se viu frustrado ao confiar na ajuda da cidade para mobilizar-se por um projeto de reordenamento cosmológico e de recomposição moral do lugar Rangel.

Em breve passeio pela Pracinha, na Rua Oswaldo Lemos, por volta das $17 \mathrm{~h}$ do dia 10 de outubro de 2017, foi possível perceber o quanto o local do crime permanece assombrado, configurando, ainda, um interdito geográfico e simbólico. Da conversa com as crianças e adolescentes ali presentes sobre o significado e a história daquela construção parada no meio do tempo, registrou-se o seguinte:

Rapaz 1: Aqui fizeram por causa do Mata Sete!

Rapaz 2: Ia ser uma Capela.

Moça: Não quero que seja uma capela, não! Quero que fique assim mesmo para a gente brincar!

Rapaz 2: Ia! Vai mais não!

Moça: Mas faz de mais de um mês que um povo veio aqui com um bocado de gente para fazer gravações. Tinha um homem que falava no microfone e tudo: 'Aqui aconteceu uma tragédia...'.

Rapaz 1: Aqui quem começou a fazer foi o Samuka ${ }^{19}$, mas parou.

Nesse ponto a conversa mudou da Pracinha para a dinâmica interacional sobre como as famílias envolvidas no crime de chacina passaram a se estranhar e ameaçar reciprocamente por causa de desentendimentos e rusgas banais cotidianos, como o caso envolvendo a disputa por uma galinha - e que foi exaustivamente escandalizado pela mídia local. E, ainda, o fato de que os vizinhos e a família chacinada 
diziam muitas coisas (ver o Processo Judicial da Chacina do Rangel) com o Carlos José (um dos autores da chacina), apesar de ser ele um rapaz trabalhador e que não mexia com ninguém.

Nessa ótica perspicaz do morador, portanto, a violência banal e cruel na forma de crime entre iguais, que chocara a cidade e sujara ainda mais a fachada do já estigmatizado Varjão/Rangel, deveria ser compreendida desde a sua lógica interacional e suas gramáticas morais e emocionais específicas. Enquanto que a narrativa pública e dramática da Chacina do Rangel, produto da ação de empreendedores morais da cidade sobre o bairro - e dos quais faziam parte aquele povo que veio aqui com um bocado de gente para fazer gravações - deveria ser compreendida como argumento moral para a intervenção simbólica, policial e urbanística no Varjão/Rangel.

O empreendimento moral de um trauma cultural como estratégia de recomposição moral do lugar poluído pela Chacina do Rangel, nesse sentido, operava a denúncia irônica e ressentida do morador em relação à cruzada simbólica sobre o bairro por parte da cidade de João Pessoa. Os elementos centrais dessa narrativa de trauma cultural eram, assim, a diferenciação entre o crime de chacina e a narrativa pública e dramática da Chacina do Rangel, bem como as sucessivas quebras de confiança produzidas na ofensiva civilizadora sobre a pobreza urbana paradigmaticamente reconhecida nas sociabilidades, na cultura emotiva e nos códigos de moralidade do Varjão/Rangel.

Interessa enfatizar, assim, que o processo de apropriação moral da chacina, em seu primeiro momento, fazia menção ao bairro do Rangel como um dado meramente geográfico, como informação de um ponto do mapa da cidade onde ocorrera um crime particularmente violento e que fortemente transgredia a normalidade normativa e as exigências civilizatórias consensualmente aceitas pela cidade. Esse ponto no mapa, um lugar obscuro da sociabilidade urbana periférica de João Pessoa, apontava para uma situação que aglutinava a um só tempo a falência dos valores familiares publicamente defendidos - isto expresso na destruição banal e cruel dos vínculos primários de confiança e confiabilidade entre vizinhos-irmãos que compartilhavam intensamente suas memó- 
rias, projetos, intimidades e destinos - e, algo ainda mais assombroso e impactante para o homem comum, a segurança ontológica mesma no outro relacional em um contexto urbano já deveras caracterizado por uma forte cultura do medo e da violência difusa.

A mídia local e alguns políticos destacados da cidade de João Pessoa e do Estado da Paraíba, nesse sentido, levantaram oportunamente os valores da família paraibana como instância moral a ser reafirmada em face do horror dos vínculos familiares e vicinais barbaramente desfeitos. Assim, um bairro com histórico policial de ser violento e socialmente estigmatizado pelas suas práticas de convivência cotidiana consideradas de baixo padrão moral - mas que até então podia ser razoavelmente enquadrado no âmbito das expectativas públicas sobre a violência urbana cotidiana, entendida e explicada pelo senso comum como resultado da pobreza e da exclusão social - passou, também, a ser definido como um lugar na e da cidade a ser urgentemente civilizado mediante procedimentos de contenção moral e de controle ostensivos, estendidos posteriormente para toda a pobreza urbana da cidade pensada como potencialmente perigosa e bárbara.

A ofensiva civilizadora dos empreendedores morais da cidade oficial, conduzida pela mídia local e encampada pela Igreja Católica e pela Administração Pública, organizou-se em torno da narrativa pública e dramática da Chacina do Rangel, também reproduzida e acomodada judicialmente em um Tribunal do Júri espetacularizado. A Igreja Católica e a Administração Pública, sob provocação da mídia local, investiram, assim, em empreendimentos morais de reordenação do social sob o argumento do sagrado religioso, no caso da retomada do lugar do crime mediante a construção de um espaço sagrado, tipo Capela ou Santuário às vítimas da chacina - e do sagrado mundano - expresso em um enorme esforço de pacificação, reurbanização e gentrificação de bairros populares e territórios perdidos para a violência através de políticas sistemáticas de planejamento e mobilidade urbana e de segurança pública.

A resposta do morador à ofensiva civilizadora da cidade oficial de João Pessoa sobre o bairro do Varjão/Rangel, nesse sentido, se reveste desde então de uma postura irônica e ressentida que busca enquadrar o 
surto descivilizador da Chacina do Rangel como um trauma cultural que, se por um lado revelou a passagem da monstruosidade pelo lugar Varjão; demonstrou também, por outro lado, as enormes limitações dos empreendedores morais locais em moralizar, pacificar, reurbanizar, gentrificar e mesmo purificar a poluição moral e emocional atribuída ao Varjão/Rangel enquanto paradigma da pobreza urbana tida como violenta e perigosa.

Os moradores do Varjão/Rangel, nesse sentido, respondem à violência cotidiana, principalmente no formato de vulnerabilidades interacionais e de estigmas, com estratégias de resiliência, articuladas em posturas de evitação irônica e ressentida. Desta maneira buscam operar a manutenção e a preservar da fachada do bairro e de sua ordem moral no contexto dos medos corriqueiros (Koury 2005) ${ }^{20}$ e da vergonha cotidiana (Barbosa 2015) em que esta se constrói.

O conceito de resiliência é aqui trabalhado de uma perspectiva da antropologia das emoções, possibilitando a análise da construção cotidiana de uma cultura emotiva enquanto jogo de tensões e conflitos. Jogos em que atores e agentes sociais produzem seus mundos simbólicos em disputas morais indeterminadas e traumáticas, sem, contudo, perderem um horizonte mínimo de continuidade e reprodução de suas práticas sociais e projetos individuais e coletivos no âmbito dos campos de possibilidades de suas relações.

Este termo busca sintetizar a capacidade do ator e agente social de se recobrar facilmente ou de se adaptar à má sorte, de superar obstáculos ou de resistir à pressão de situações adversas ou a mudanças traumáticas decorrentes de experiências de ruptura e quebra de confiança em seu cotidiano de normalidade normativa. A resiliência, com efeito, aponta para as competências do ator e agente social em lidar crítica e reflexivamente com suas memórias traumáticas e com seus projetos frustrados ou idealizados.

Deste modo, a resiliência aponta para o esforço individual e coletivo de negociação da situação, mesmo quando os custos emocionais são altos e as expectativas de realização são baixas ou nenhuma. A ironia, a jocosidade e o sarcasmo figuram, assim, como formas elaboradas de deslocar-se em situações de engolfamento e vergonha-desgra- 
ça (Scheff 2011 e 2013). Este deslocamento combina, portanto, duas estratégias de violência simbólica: a ironia e o ressentimento.

Em um cojunto de imagens produzidas em vários pontos do Varjão/Rangel, foi possível, nesse sentido, captar elementos da cultura emotiva irônica e ressentida de um bairro que luta por reconhecimento na cidade oficial de João Pessoa. Expressões que modulam acusações indiretas aos empreendedores morais da cidade oficial, que deveriam cuidar do bairro, estas imagens compreendem facetas do empreendedorismo moral do morador do Varjão/Rangel.
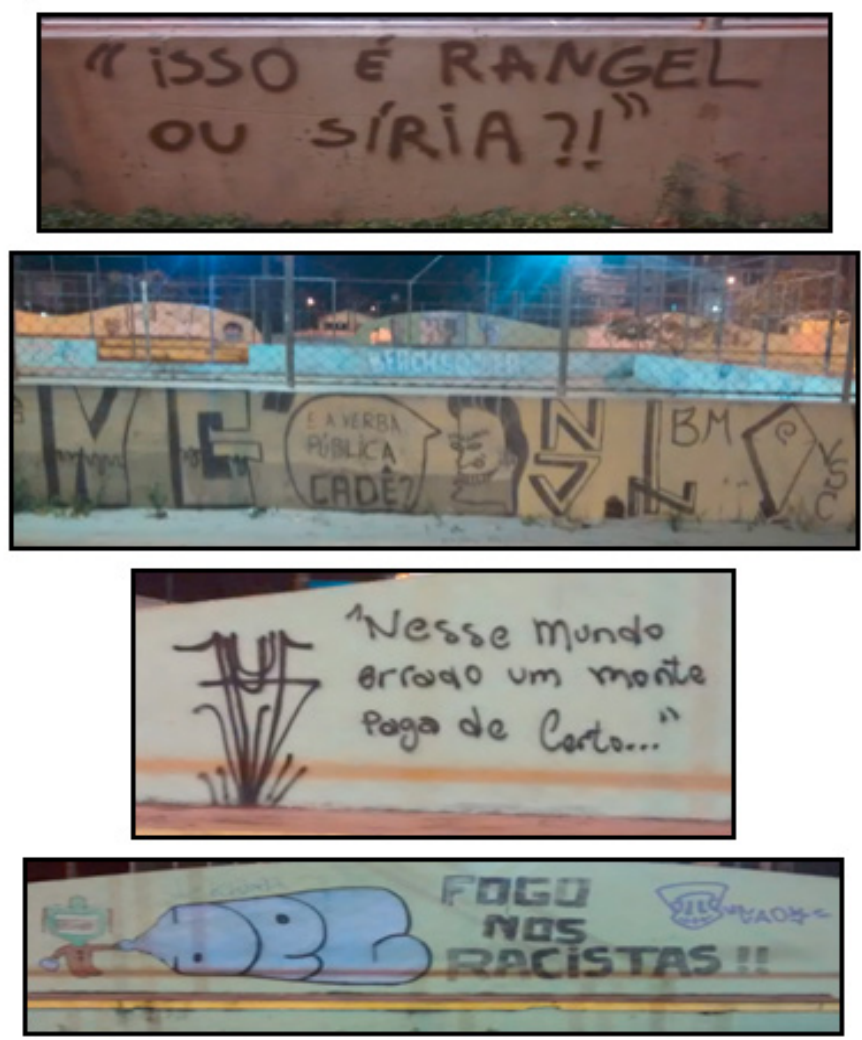

Fig. 1 - Grafite na Praça da Amizade denuncia a violência difusa e o descaso da Administração Pública em relação ao Varjão/Rangel, chamando também atenção para o estigma que pesa sobre o bairro. Fonte: Arquivos do GREM. 
Nas imagens captadas na Praça da Amizade, ponto de encontro central para â sociabilidade de lazer dos moradores, o grafite chama a atenção para o descuido da Administração Pública em relação ao bairro, cotidianamente vivenciado nos projetos públicos inconclusos e na violência difusa, com mensagens como: "isso é Rangel ou Síria?!", "E a verba pública cadê?", "Nesse mundo errado um monte paga de certo", "Fogo nos racistas!!”.

Ainda nas proximidades da Praça da Amizade, na Avenida 02 de Fevereiro, corredor cental do Varjão/Rangel no sentido Centro-Zona Sul de João Pessoa, uma mensagem de GATO, personagem recorrente na cena juvenil do bairro, explora a indignicação do modor do bairro em relação à violência difusa e à criminalidade organizada que faz uso do lugar Rangel em conivência com os empreendedores morais da cidade: "Pra q essa guerra injusta. Quem trousse as armas para os pobres sem estudo rouba se desespera".

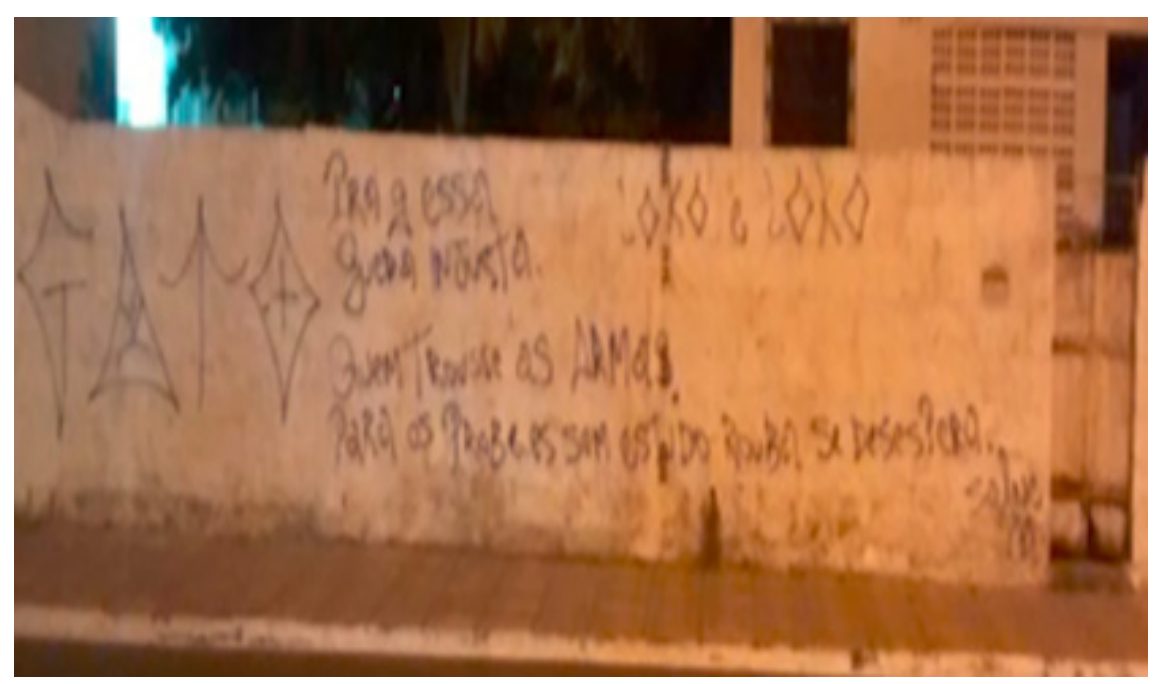

Fig. 2 - Grafite na Avenida 02 de Fevereiro denuncia a violência difusa e a criminalidade organizada no Varjão/Rangel. Fonte: Arquivos do GREM. 
Em paralelo a esta mensagem, chamou a atenção um grafite na Rua da Mata ou Rua São Geraldo, um dos pontos mais precarizados do Varjão/Rangel e também considerado como uma das áreas de maior circulação de produtos ilícitos. A mensagem, nesse caso, é de afirmação dos grupos juvenis ligados a torcidas organizadas e pequenas gangues, os engraçadinhos do bairro: "Em terra de Okaida o Flamengo reina! Paz -Liberdade - Fechado P.K. - OKD”.

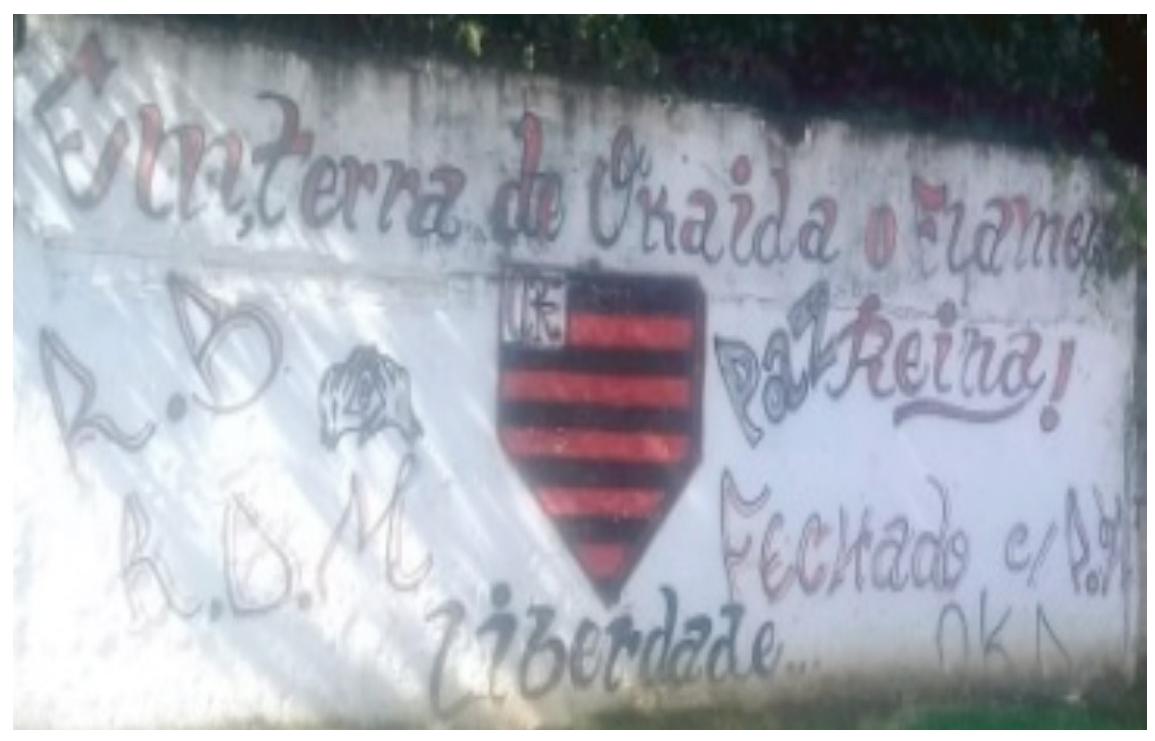

Fig. 3 - Grafite na Rua da Mata ou Rua São Geraldo com alusão a atividades de gangues juvenis ligadas a torcidade de futebol e ao crime organizado, no Varjão/ Rangel. Fonte: Arquivos do GREM.

A pobreza urbana, com efeito, vê-se a si mesmo, em muitos sentidos, a partir do olhar envergonhado e moralizante do empreendedor moral da cidade que lhe qualifica como desvalor e como contexto interacional inverso ao da fachada que a cidade busca oficialmente performatizar. Deste modo, o morador se ressente da possibilidade de vir a ser envergonhado e amedrontado a qualquer momento, mas, como 
se pode deduzir das mensagens em forma de pixo e grafite, supracitadas, busca apropriar-se dessa situação de desvalor e estigma a partir de um discurso irônico de acusação dos empreendedores morais locais e de trauma cultural como condição da cultura emotiva do Varjão/ Rangel, colonizando, assim, até mesmo o local do crime de chacina, elemento simbólico central para a narrativa pública e dramática da Chacina do Rangel, e transformando-o na atual pracinha: ainda que permaneça como lugar assombrado, um lugar interdito e perpassado por silêncios e cuidados, vem paulatinamente sendo transformado em um lugar de encontros e jogos para os moradores do bairro, em especial da Rua Oswaldo Lemos.

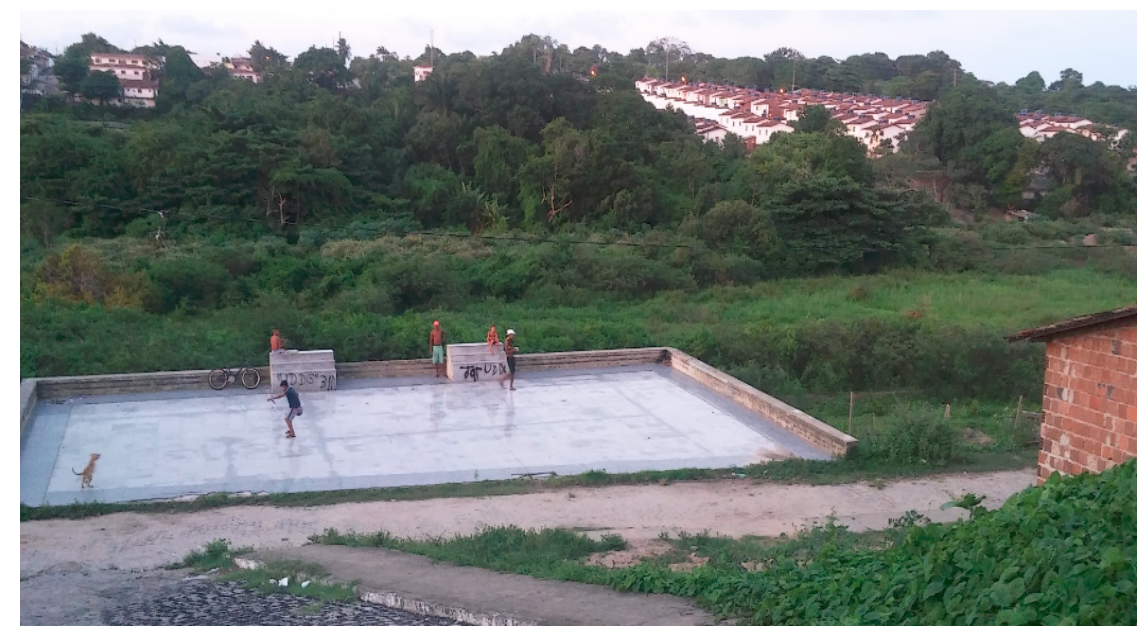

Fig.4 - Imagem da obra pública inconclusa do Monumento à Paz, transformada simbolicamente pelos moradores do Varjão/Rangel na pracinha. Fonte: Arquivos do GREM.

A Pracinha pode ser apontada como um dos mais importantes esforços do empreendedorismo do morador do bairro no sentido da recomposição moral e emocional da ordem cosmológica, da cultura 
emotiva e dos códigos de moralidade do Varjão/Rangel. Recomposição moral esta que vem sendo elaborada desde o fatídico 09 de julho de 2009, quando o crime banal e cruel de chacina entre iguais começou a ser apropiado pelos empreendedores morais da cidade como narrativa de surto descivilizador e falência moral da Chacina do Rangel.

Um registro no diário de campo de 30 de abril de 2017 resume bem este sentimento de desvalor e envergonhamento do morador local, articulado, porém, com uma postura de resiliência. Em um breve discurso proferido de improviso para uma multidão de jovens que acompanhavam o seu show, em frente ao CAC do Rangel ${ }^{21}$, no domingo anterior ao feriado do Dia do Trabalhador, assim se expressou um dos artistas do bairro, visivelmente emocionado: "O Rangel é o bairro do carinho, do amor e do respeito... mas ninguém dá oportunidade".

Este artigo buscou analisar os impactos morais e emocionais do crime de chacina transformado em narrativa pública e dramática da Chacina do Rangel e em argumento de ofensiva civilizadora dos empreendedores morais da cidade oficial de João Pessoa no cotidiano dos moradores do Varjão/Rangel. Valeu-se, assim, de uma abordagem etnográfica sobre a cultura emotiva e os códigos de moralidade que caracterizam as sociabilidades no bairro desde então, mas também no contexto da relação bairro-cidade e em perspectiva histórica de evolução urbana da cidade.

Nesse sentido, a discussão girou em torno das ações de empreendedorismo moral da mídia local e da administração pública, enquanto empreendedores morais da cidade oficial responsáveis pela midiatização da narrativa moralizante de Chacina do Rangel e, ato contínuo, pela judicialização desta narrativa midiática; e também girou em torno do empreendedorismo moral dos moradores do bairro em face do estigma que pesa sobre o Varjão/Rangel. Estigma este potencializado pela escandalização midiática do crime de chacina ali ocorrido como surto descivilizador e como falência moral e em cujo contexto o morador respondeu com estratégias ressentidas e irônicas de recomposição moral no sentido de uma narrativa inversa de trauma cultural. 


\section{Notas:}

1 Os dados apresentados e debatidos ao longo deste trabalho foram produzidos na pesquisa de doutorado conduzida no Programa de Pós-Graduação em Antropologia PPGA da UFPE, entre março de 2015 e março de 2019, sob orientação da Profa. Dra. Roberta Bivar Carneiro Campos e sob co-orientação do Prof. Dr. Mauro Guilherme Pinheiro Koury. A pesquisa foi organizada a partir de uma estratégia metodológica de imersão de longa duração no campo de pesquisa, o bairro do Varjão/ Rangel, de modo que o pesquisador pode etnografar o cotidiano da cultura emotiva do bairro enquanto morador atípico, isto é, desde uma perspectiva distanciada e crítica de percepção dos modos de ação e de realidade nativos. Nesse sentido, a pesquisa se desdobrava metodologicamente como empreendimento etnográfico, de observação participante e de observação objetificante, de conversas informais, de montagem de bancos de imagens e de notícias de jornais sobre o bairro e sobre a relação bairro e cidade, de levantamento de documentos oficiais e de narrativas oficiosas sobre os lugares Varjão e Rangel, entre outros.

2 Por cidade oficial se entende a instância moral representada por empreendedores morais (Becker, 2008) locais capazes de mobilizar amplas parcelas da opinião pública - como a mídia da cidade e a Igreja Católica - ou de recursos materiais e humanos para a intervenção na ordem e na dinâmica social, como a Administração pública.

3 A ofensiva civilizadora (Regt 2017) constitui, em linhas gerais, o ritual público, no sentido gusfieldiano de transformação de problemas sociais - como a violência generalizada e difusa - em problemas públicos e políticos, como um programa de ação ou política pública de melhoria e embelezamento da cidade ou no combate à violência urbana imputado à pobreza ou a regiões de pobreza, como as periferias pobres. A ofensiva civilizadora abarca, ainda, a consequente e sistemática intervenção de empreendedores morais para a mudança (ou para a performatização da mudança), em curto prazo, de aspectos pontuais ou mesmo mais amplos do habitus (Elias 1997 e 2009) de uma população classificada como passível de moralização, no sentido dos padrões morais da civilização moderna ocidental.

4 Bairro de dois nomes, um oficial, Varjão, outro oficioso, Rangel (Koury 2014). Este último produto de uma luta dos moradores para restaurar a imagem pública do bairro, tido como violento, em relação aos demais bairros, e à cidade de João Pessoa, como um todo, como forma de inclusão e reconhecimento social como bairro civilizado, 'bairro do amor' e 'bom de viver'.

5 A narrativa de trauma cultural dos moradores do Varjão/Rangel progressivamente se diferencia da narrativa dos empreendedores morais da cidade oficial para, ato contínuo, buscar salvaguarda a fachada moral e emocional do Varjão/Rangel como lugar de pessoas de bem.

6 Extraído de leituras de Becker (2008), mas também enriquecido a partir dos conceitos de cruzado simbólico, de Gusfield (1986), de especialista, de Giddens (2002), e de dramatis personae, de Geertz (2012), o conceito de empreendedores morais aponta para a ação pública de atores e agentes sociais destacados no espaço público, e também político, de uma sociabilidade dada. Os empreendedores morais, nesse sentido, 
atuam como articuladores de agendas sociais de intervenção pública e de transformação social, ou como fazedores de novas regras morais ou como figuras e personagens ritualmente influentes na definição das situações e dos problemas sociais de um contexto interacional e societal específico.

7 Goffman (2012: 534-600) entende por vulnerabilidades interacionais as vulnerabilidades da experiência enquadrada, o que significa a possibilidade sempre presente de enganos e manipulações, desentendimentos e mal-entendidos, assimetrias informacionais, expectativas frustradas e quebra de confiança no jogo comunicacional. Desta forma, Goffman chama a atenção para o caráter processual, imprevisível e criativo da ordem interacional, que oscila entre consensos e dissensos circunstancialmente negociados, tensos e conflituais. As vulnerabilidades interacionais, pensadas principalmente a partir de categorias analíticas goffmanianas (Goffman 2012a), são também problematizadas com base no que Arendt (2010) entende por fragilidade dos assuntos humanos. Fragilidade esta inerente ao mundo da ação e do discurso, ou seja, ao espaço-entre subjetivo que constitui a teia de relações humanas.

8 Ultimamente o lugar vem sendo utilizado por crianças e adolescentes da Rua Oswaldo Lemos, da Rua Rangel Travassos e arredores que o transformaram em uma quadra improvisada de futsal e de baleado (jogo em que duas equipes rivais buscam acertar a outra atirando uma bola de borracha de tamanho médio; também conhecido como queimado ou jogo do mata), em ponto para empinar pipa e em salão ao ar livre para encontro de passarinheiros do Varjão/Rangel. O lugar, assim, foi apropriado moralmente pelo morador do bairro, ainda que permaneça como um lugar interdito para muitas atividades cotidianas tidas como não condizentes e desrespeitosas para com a memória do evento trágico ali ocorrido.

9 Muito pelo contrário, ali se vê o morador à vontade, com portas e janelas abertas, organizando seu lazer de final de semana na própria rua, literalmente; trata-se, assim, de uma região moral ou de um mundo social fortemente regido por códigos de reconhecimento, solidariedade, amizade e pertença. A tradição comunitária é vivida na fofoca e na jocosidade diária e na partilha de destinos laborais e domésticos marginalizados e envergonhados pelo olhar modernizante da cidade de João Pessoa. 10 Entre a vítima e o agressor da chacina havia um regime de dádiva e de trocas de favores que se expandia para as duas famílias envolvidas no crime: ambas formavam uma comunidade de afetos. Carlos José Soares, que veio a tornar-se nacionalmente famoso como o 'Monstro do Rangel', foi levado e iniciado no ofício de gesseiro por Moisés Soares Forte.

11 O Processo Judicial do caso da Chacina do Rangel (Processo $\mathrm{N}^{\circ}$ 200.2009.023.125-5) explorou exaustivamente a íntima relação entre as famílias de agressores e vítimas, enfatizando como a confiança e o respeito que as unia foram paulatinamente esgarçados por práticas de fofoca depreciativa, de jocosidade agressiva e de pequenas agressões físicas.

12 Ver em Zamboni (2009) a discussão sobre a questão da confiança na teoria social.

13 Cooley (2017), nesse sentido, enfatiza a noção de self autoespelhado como elemento central da indeterminação do jogo comunicacional. Goffman (1998), por sua vez, discute a tensão no jogo interacional de enfrentamento de fachadas indi- 
viduais e coletivas, assumidas e negociadas a cada enquadramento situacional, com todos os riscos e perigos inerentes aos encontros e desencontros possíveis, e jamais per si determinados, de atores e agentes sociais formando e rompendo alianças.

14 A ação da Justiça, como empreendedor moral e cruzado simbólico, foi detidamente analisada no capítulo 5 da minha tese.

15 Dona Neuza é um nome fictício, assim como os demais nomes empregados nas referências aos moradores do bairro do Varjão/Rangel, salvo algumas poucas exceções de nomes de personagens reais amplamente divulgados pelas mídias sociais e de conhecimento público da cidade de João Pessoa.

16 O empreendimento moral dos moradores do Varjão/Rangel, enquanto bairro e identificação coletiva, caracteriza-se pelo exercício individualizado, difuso e ressentido de ironias direcionadas às autoridades públicas e aos demais empreendedores morais da cidade oficial de João Pessoa; mas, também, de ações que se acumulam no sentido do investimento coletivo no valor do bairro, tais como autoconstruções que afirmam o desejo de ficar no bairro e o consumo e a propagação da marca Rangel como estilo de vida da periferia culturalmente denso e rico. Nesse duplo movimento de valorização de si e de acusação do outro - a cidade oficial que não entende e, por isso, estigmatiza o bairro - os moradores tecem lentamente uma narrativa de trauma cultural em torno do crime de chacina.

17 A comitiva de moradores do Varjão/Rangel, que se posicionava publicamente em relação aos desdobramentos dos processos de apropriação moral e emocional do crime de chacina transformado em Chacina do Rangel, era então composta, em seu núcleo duro, por familiares das vítimas e por vizinhos da Rua Oswaldo Lemos e ruas adjacentes próximas, e por moradores solidários e chocados em geral, que se mobilizavam desde todos os pontos do bairro. Cabe enfatizar as densas redes homofílicas e de intensa pessoalidade que cruzam o Varjão/Rangel, sendo este um lugar de parentes, de primos, de vizinhos e de conhecidos. Quando, a título de exemplo, o pesquisador teve a oportunidade de conversar com o morador responsável pela administração do cemitério em que as vítimas do crime de chacina foram sepultadas, o mesmo afirmou o seu parentesco por afinidade com o Mata Sete ou Monstro do Rangel, razão pela qual ele se envergonhava e, como pessoa de vergonha, buscava "fazer a parte dele" em pedir desculpas à cidade de João Pessoa.

18 Nessa lista de promessas descumpridas, a credibilidade da mídia local e da Igreja Católica, por exemplo, foram severamente abaladas com a falência do projeto oportunista de construção de uma Capela ou Santuário dedicado às vítimas da chacina no local do crime; projeto este de certa forma retomado pela Administração Pública - atualmente também desacreditada - no esforço de construção de um Monumento à Paz, mas também jamais concluído.

19 Conhecido apresentador de programa televisivo sensacionalista sobre a violência cotidiana na cidade e que faz uso de sua popularidade para fins políticos.

20 Os medos, corriqueiros quando conformam o cotidiano e o imaginário do homem comum, condicionam fortemente a estruturação dos projetos e identidades individuais e coletivos, apontando, enquanto emoção específica, para como se articulam a relação entre indivíduo e sociedade, a própria cultura emotiva e os códigos de moralidade de uma sociabilidade concreta. 
21 Centro recreativo local e um dos símbolos da cultura emotiva e dos códigos de moralidade o Varjão/Rangel na cidade de João Pessoa.

\section{Referências:}

ADAMS, Richard N. 2007. La Red de la Expansion Humana. México: Centro de Investigaciones y Estudios Superiores en Antropologia Social/ Universidad Autonoma Metropolitana/ Universidad Iberoamericana.

ALBERONI, Francesco. 1981. Enamoramento e Amor. São Paulo: Círculo do Livro. ALEXANDER, Jeffrey C. 2004. "Toward a Theory of Cultural Trauma." In ALEXANDER, J. et al (eds.): Cultural Trauma and Collective Identity, pp. 21-65. Berkley /Los Angeles /London: University of California Press.

ANSART-DOURLEN, Michèle. 2009. "O ressentimento e a igualdade: contribuição para uma antropologia filosófica da democracia”. In BRESCIANI, S. \& NAXARA, M. (eds.): Memória e (res)sentimento: indagações sobre uma questão sensivel, pp. 347-365. Campinas: EdUNICAMP.

ARENDT, Hannah. 2010. A Condição Humana. Rio de Janeiro: Forense Universitária.

BARBOSA, Raoni Borges. 2015. Medos Corriqueiros e Vergonha Cotidiana: Um Estudo em Antropologia das Emoções. Recife/ João Pessoa: Editora Bagaço/ Edições do GREM.

BECKER, Howard S. 2008. Outsiders: estudos de sociologia do desvio. Rio de Janeiro: Jorge Zahar.

BERGER, Peter. 2001. Perspectivas Sociológicas: uma visão humanística. Petrópolis: Vozes.

CARDOSO DE OLIVEIRA, Luís Roberto. 2008. "Existe violência sem agressão moral?" Revista Brasileira de Ciências Sociais, 23(67):135-146.

2011. Direito Legal e Insulto Moral: Dilemas da Cidadania no Brasil, Quebec e EUA. Rio de Janeiro: Garamond.

COELHO, Maria Cláudia. 2010. "Narrativas da violência: a dimensão micropolítica das dimensões.” Mana, 16(2):265-285.

COOLEY, Charles H. 2017. "O self social e o significado do Eu”. RBSE - Revista Brasileira de Sociologia da Emoção, 16(47):173-192.

ELIAS, Norbert. 1997. Os Alemães: a luta pelo poder e a evolução do habitus nos séculos XIX e XX. Rio de Janeiro: Jorge Zahar. . 2009. Los Alemanes. Buenos Aires: Nueva Trilce.

GEERTZ, Clifford. 2012. Atrás dos Fatos. Dois países, quatro décadas, um antropólogo. Petrópolis: Vozes.

GIDDENS, Anthony. 2002. Modernidade e Identidade. Rio de Janeiro: Jorge Zahar Editora. 
GOFFMAN, Erving. 1998. "Footing”. In RIBEIRO, B. \& GARCEZ P. (eds.): Sociolingüística Interacional: Antropologia, Linguistica e Sociologia em Análise do Discurso, pp. 11-25. Porto Alegre: AGE Editora. . 2012. Os Quadros da Experiência Social: Uma perspectiva de análise. Petrópolis: Vozes. . 2012a. Ritual de Interação: ensaios sobre o comportamento face a face. Petrópolis: Vozes.

GUSFIELD, Joseph R. 1986. Symbolic Crusade: Status Politics and the American Temperance Movement. Chicago: University of Illnois Press.

HUGHES, Everett C. 2013. "As boas pessoas em trabalho sujo". In COELHO, M. C. (ed.): Estudos sobre interação: textos escolhidos, pp. 91-108. Rio de Janeiro: Ed. UERJ.

KOURY, Mauro. 2005. Medos Corriqueiros e Sociabilidade. João Pessoa: Edições GREM/Editora Universitária UFPB. . 2016. Quebra de confiança e conflito entre iguais: cultura emotiva e moralidade em um bairro popular. Recife/ João Pessoa: Edições Bagaço/ Edições GREM. .2014. "Solidariedade e conflito nos processos de interação cotidiana sob intensa pessoalidade". Etnográfica, 18(3):521-549.

KOURY, M., ZAMBONI, M. \& BRITO, S. 2013. "Como se articulam vergonha e quebra de confiança na justificação da ação moral”. Dilemas: Revista de Estudos de Conflito e Controle Social, 6(2):251-268.

. 2010. "Confiança e Vergonha: Uma análise do cotidiano da moralidade". Trabalho apresentado no Seminário Temático "Antropologia e Sociologia da Moral", $34^{\circ}$ Encontro Anual da ANPOCS, Caxambu - MG.

PARSONS, T. et al. 1970. "Papel e sistema social". In CARDOSO, F. H. \& IANNI, O. (eds.): Homem e Sociedade: Leituras básicas de sociologia geral, pp. 63 68. São Paulo: Companhia Editora Nacional.

REGT, Ali de. 2017. "Ofensiva civilizadora: do conceito sociológico ao apelo moral”. Revista Brasileira de Sociologia da Emoção, 16(47):137-153.

REZENDE, Cláudia \& COELHO, Maria Cláudia. 2010. Antropologia das Emoções. Rio de Janeiro: Editora FGV.

SCHEFF, Thomas J. 1990. Microsociology: Discourse, emotion, and social structure. Chicago: University Of Chicago Press. . 2011. "A vergonha como a emoção principal da análise sociológica. Alguns exemplos nas músicas populares”. RBSE - Revista Brasileira de Sociologia da Emoção, 10(28):74-86.

. 2013. "Desvendando o processo civilizador: vergonha e integração na obra de Elias". RBSE - Revista Brasileira de Sociologia da Emoção, 12(35):637-655.

SCHEFF, Thomas \& RETZINGER, Suzanne. 1991. Violence and Emotions. Lexington: Lexington Books.

SIMMEL, Georg. 2003. "Fidelidade: Uma tentativa de análise sócio-psicológica". RBSE - Revista Brasileira de Sociologia da Emoção, 2(6):513-519. 
SIMMEL, Georg. 2010. "Gratidão: Um experimento sociológico". RBSE - Revista Brasileira de Sociologia da Emoção, 9(2):785-804.

WERNECK, Alexandre. 2015. ''Dar uma Zoada', 'Botar a Maior Marra': Dispositivos Morais de Jocosidade como Formas de Efetivação e sua Relação com a Crítica". DADOS - Revista de Ciências Sociais, 58(1):187-221.

ZAMBONI, Marcela. 2009. 'Quem acreditou no amor, no sorriso, na flor': A confiança nas relações amorosas. Tese de Doutorado. Recife: UFPE.

\begin{abstract}
This article analyzes the moral and emotional impacts on the everyday life of the residents of a popular neighborhood in the city of João Pessoa - PB, the Varjão / Rangel, of a banal and cruel crime, among equals, occurred in 2009. The analysis starts from the ethnographic reports of the residents of Varjão / Rangel in relation to the various moralizing attempts of their place of belonging, in order to try to understand the resentful and ironic stance that developed in the process of moral recomposition of the normative normality of the neighborhood since the outbreak of violence that shocked and embarrassed the residents of Varjão / Rangel. It is an effort to understand the tense relationship of morality building and conduct imposition in relation to the moral uses of a situation of shame-disgrace from the moral enterprises, in the form of a cultural trauma, of the residents of the neighborhood of Varjão / Rangel.
\end{abstract}

Keywords: Bankruptcy and moral recomposition, Resentment and irony, Enterprise and moral appropriation, Neighborhood of Varjão/Rangel

Recebido em Abril de 2019.

Aprovado em Julho de 2019. 